\title{
O suspiro manipulado do consumidor oprimido: reflexões a partir de Benjamin, Alves e Tillich
}

\author{
João Henrique Stumpf* \\ Pablo Fernando Dumer**
}

\begin{abstract}
RESUMO
A partir das abordagens de Rubem Alves e Paul Tillich sobre a religião, o artigo analisa como o capitalismo, caracterizado por Walter Benjamin como religião, utiliza-se da aspiração humana pelo transcendente ao direcionar o caos humano para o consumo. O artigo faz um breve mapeamento sobre as consequências, chamando a atenção para seus efeitos colaterais e as vítimas que tal lógica produz. Os seres humanos não conseguem viver sem possibilidades de realização plena e, por isso, aspiram por algo que transcenda a realidade opressora da vida. É nesse ponto que está localizada a origem da experiência religiosa. $\mathrm{O}$ capitalismo moderno consegue usar desse aspecto religioso humano para o consumo. A crítica teológica é importante nesse contexto. O parâmetro que orientou a escolha de Alves e Tillich como base do artigo são suas respectivas abordagens sobre o fenômeno religioso, bem como a delimitação de espaço.
\end{abstract}

Palavras-chave: Religião. Capitalismo. Walter Benjamin. Rubem Alves. Paul Tillich.

* Bacharel em Teologia pelas Faculdades EST. Mestre em Teologia Prática pelo Programa de Pós Graduação das Faculdades EST. Pesquisador no doutorado acadêmico das Faculdades EST na área da diaconia e missão. E.mail: joaohenriques131@gmail.com.

** Bacharel em Teologia, mestre em Teologia Sistemática pela Faculdades EST e, atualmente, realiza pesquisa de doutorado com apoio da CNPq, na Faculdades EST, São Leopoldo, Rio Grande do Sul, Brasil. 


\title{
THE SUSPICED MANIPULATED OF THE OVERPRICED CONSUMER: REFLECTIONS FROM BENJAMIN, ALVES AND TILLICH
}

\begin{abstract}
In the light of Rubem Alves and Paul Tillich approaches to the religion, this article analyzes how capitalism - characterized by Walter Benjamin as religion - uses human longing for the transcendent, by directing human chaos for consumption. This article presents a short mapping of the consequences, raising awareness of side effects and taking to account the victims that this logic produces. Humans cannot live without chances of fulfillment and, therefore, aspire for something beyond the oppressive reality of life. It is at this point that the origin of religious experience is located. Modern capitalism can use this human religious aspect to the consumer. The theological critic is important in that context. The parameter that guided the choice of Alves and Tillich as the basis of the article are their respective approaches on the religious phenomenon, as well as the delimitation of space.
\end{abstract}

Key-words: Religion. Capitalism. Walter Benjamin. Rubem Alves. Paul Tillich.

\section{Considerações Iniciais}

Dados recentes demostram que a desigualdade social no mundo aumentou profundamente desde 1980 e a previsão é de que continue aumentando nas próximas décadas (AFT, 2017). O grupo do 1\% mais rico da população mundial concentrou, em $2017,82 \%$ de toda a riqueza produzida (GOMES, 2018). Tais dados atestam que a lógica da acumulação sem limites, não só permitida, mas também promovida pelo sistema capitalista, vem se concretizando com sucesso. Se por um lado a concentração de riqueza nas mãos de poucos cresce, por outro, a miséria e a fome aumentam consideravelmente. Segundo dados de 2017 da ONU "mais de 800 milhões de pessoas no mundo todo continuam vivendo em extrema pobreza e muitas estão ameaçadas por altas taxas de desemprego, insegurança, desigualdade, conflito, assim como efeitos das mudanças climáticas" (ONU, 2017). No Brasil, após um período 
de diminuição da pobreza, a mesma volta a crescer significativamente e já atinge $22 \%$ da população nacional (CUNHA, 2017). Fato é que o empobrecimento e a miséria aparecem como consequência direta da acumulação de riqueza nas mãos de poucos. Ao mesmo tempo em que essa tese parece obvia, pode-se perceber que não é compartilhada entre a maioria da população pobre. A riqueza, geralmente, não é vista com maus olhos pela população economicamente carente, pelo contrário, boa parte acredita na meritocracia. Por que isso acontece? Por que os pobres não percebem que estão sendo explorados e oprimidos ou, mesmo quando percebem, não se revoltam contra a estrutura capitalista que os condena a uma vida miserável?

Tais questionamentos não são inéditos. Vários pesquisadores, ao longo da história já se perguntaram sobre os elementos presentes no sistema capitalista que dificultam ou impedem que pessoas, mesmo sendo exploradas e oprimidas, não percebam e aceitam isso de forma passiva. Importantes contribuições, nessa direção, foram dadas por pesquisadores que se propuseram a analisar a relação entre o sistema capitalista e a religião. Benjamin, quando definiu o capitalismo como um fenômeno essencialmente religioso, previa que a sua dimensão religiosa ficaria mais clara com o passar do tempo. Seguindo a sua previsão, o presente artigo buscará estabelecer um diálogo entre aspectos do sistema capitalista moderno, especialmente em sua dimensão consumista, com os conceitos sobre religião sustentados por Rubem Alves e Paul Tillich.

Nosso objetivo é entender até que ponto o sistema capitalista, em suas várias facetas e dimensões, consegue dar conta de responder ou dialogar com a aspiração humana pelo transcendente, aquilo que Rubem Alves denomina como experiência religiosa primordial e Paul Tillich, de preocupação última. Para dialogar com tal objetivo o artigo foi estruturado em três tópicos que buscam desenvolver a discussão. $\mathrm{O}$ primeiro analisa os conceitos de religião sustentados e desenvolvidos em Paul Tillich e Rubem Alves. O tópico posterior discute a relação entre os conceitos de religião dos referidos autores com elementos presentes no sistema capitalista contemporâneo. Por fim, o terceiro tópico analisa de que forma o elemento medular do sistema capitalista contemporâneo, 
a saber, o consumismo, dialoga com aquilo que Rubem Alves e Paul Tillich entendem por religião.

A pesquisa constitui-se em um estudo de cunho teórico bibliográfico, de aproximação analítica e crítica, sem a pretensão de apontar soluções práticas. Por questões de delimitação de espaço a pesquisa ocupa-se somente com o pensamento de Alves e Tillich acerca da religião.

\section{Religião a partir de Rubem Alves e Paul Tillich}

O foco da análise de Rubem Alves, teólogo protestante brasileiro é diferente do assumido pelos filósofos do século XIX. Alves tem em mente a origem de toda forma institucionalizada de religião: as experiências religiosas primordiais (ALVES, 2007, p. 39). Enquanto Marx, Nietzsche e Feuerbach denunciam uma institucionalização usada para a dominação e opressão de uns sobre outros, Alves explicita o fato que antecede tudo isso. Para ele, a religião em sua essência não é algo externo, institucionalizado, mas é uma necessidade humana de transcender a materialidade opressora da vida. Um jeito de pôr ordem no caos. As formas institucionalizadas de religião são tentativas de prender em conceitos e estruturas o mistério da experiência (ALVES, 2007, p. 39-40).

Alves busca a essência da experiência religiosa, na qual a imaginação é vista como um dado fundamental. "Realiza-se, então, na liturgia da imaginação, a mais alta pretensão mágica da consciência: a criação de um mundo à imagem e semelhança do homem" (ALVES, 2007, p. 52). É nesse nível que Alves detecta a origem da religião: “o conflito entre o projeto inconsciente do ego de encontrar um mundo que possa ser amado, e a dura realidade do mundo objetivo, que ignora totalmente as exigências do coração" (ALVES, 2007, p. 52). Assim, a religião é a criação humana de um mundo onde o ser humano possa se realizar, onde posso viver uma vida com abundância.

Para Alves, a principal diferença entre o ser humano e o restante das criaturas é o fato deste não se aceitar, se contentar, ou mesmo, se acomodar com aquilo que é. Tal característica gera a criatividade, a imaginação, que o leva a transcender-se (ALVES, 2013, p. 17-20), não se conformando em viver uma vida caótica, sem sentido, mas buscando 
vivenciar aquilo que a realidade lhe nega. A religião é a aspiração humana por aquilo que lhe falta, por horizontes utópicos, busca das realidades pelas quais se anseia, mas que a realidade nega, busca de sentido para aquilo sem sentido, enfim, uma forma de tentar colocar ordem no caos da existência (ALVES, 2013, p. 125).

Paul Tillich, teólogo protestante teuto-estadunidense, define a religião de maneira semelhante, mas, ao invés de falar em uma experiência primordial, fala em preocupação última (ultimate concern). Para Tillich:

A preocupação religiosa é última. Ela despoja todas as outras preocupações de uma significação última. Ela as transforma em preliminares. A preocupação última é incondicional, independente de qualquer condição de caráter, desejo ou circunstância. A preocupação incondicional é total: nenhuma parte de nós mesmos ou de nosso mundo está excluída dela. Não há "lugar" onde nos possamos esconder dela. A preocupação última é infinita: nenhum momento de relaxamento ou descanso é possível em face de uma preocupação religiosa que é última, incondicional, total e infinita (TILLICH, 2011, p. 29).

Para Tillich, portanto, a religião possui caráter existencial e envolve a totalidade da existência do ser humano e suas relações. Não há aspecto da vida humana nem da cultura humana que não possua uma profundidade religiosa, isto é, a preocupação religiosa, que é última, condiciona todas as demais preocupações e realizações humanas. Em outras palavras, a religião, enquanto preocupação última, "é a substância que dá sentido à cultura, e a cultura, por sua vez, é a totalidade das formas que expressam as preocupações básicas da religião. Em resumo: religião é a substância da cultura e a cultura é a substância da religião" (TILLICH, 2009, p. 87).

A partir dessa definição de religião como preocupação última, fé, para Tillich, "é estar possuído por aquilo que nos toca incondicionalmente" (TILLICH, 2002, p 5). Segundo Tillich, o ser humano possui diversas preocupações na vida, muitas das quais são urgentes como alimento e moradia. Nisso o ser humano não é diferente de qualquer outro ser vivo. O ser humano, porém, possui outras preocupações além destas. Ele possui "preocupações espirituais, isto é, estéticas, sociais, políticas e cognitivas" (TILLICH, 2002, p. 
5). A preocupação última, portanto, transcende a mera sobrevivência, não se dirige a bens que garantam esta sobrevivência, mas por símbolos que lhe confiram identidade. Mais do que exigir a pessoa por completo, a preocupação última contém a promessa de "realização última" (TILLICH, 2002, p. 6), ou seja, a vida plena onde a alienação está superada, onde a existência está reconciliada. A busca pelo transcendente é, assim, uma busca pela realização última, plena e incondicional do ser humano.

Constatamos, portanto, que a religião é uma necessidade humana, tanto para Alves como para Tillich. A aspiração humana pelo transcendente pode ser ilustrada como um ato de respiração que procura por "ares saudáveis", realidades libertadoras mesmo que utópicas, mas que possam oferecer sentido para a realidade sem-sentido da vida.

\section{O sistema capitalista e a religião}

Walter Benjamin foi um influente filósofo judeu alemão no século XX da Escola de Frankfurt. Ele inicia o livro $O$ capitalismo como religião afirmando que "O capitalismo deve ser visto como uma religião", pois, "está essencialmente a serviço da resolução das mesmas preocupações, aflições e inquietações a que outrora as assim chamadas religiões quiseram oferecer respostas" (BENJAMIN, 2013, p. 21). Esta afirmação é corajosa. Benjamin vai além de Weber ao afirmar que o capitalismo não é só condicionado pela religião, ou mesmo além de Marx por afirmar que o capitalismo não é só aliviado pela religião, mas também "um fenômeno essencialmente religioso" (BENJAMIN, 2013, p. 21). Com esta definição de religião, o filósofo se aproxima muito da definição de Alves e Tillich, ou seja, como uma experiência primordial, uma preocupação existencial.

Assim como em Tillich, onde a preocupação religiosa exige o ser humano por completo, presente em todos os âmbitos, espaços e momentos, também o capitalismo é, para Benjamin, um culto onde “não existe 'dias normais', não há dia que não seja festivo no terrível sentido da ostentação de toda a pompa sacral, do empenho extremo do adorador" (BENJAMIN, 2013, p. 21-22). Se para Tillich a religião está na profundidade de todas as realizações humanas, o capitalismo, 
para além de um modo de produção, mas como fenômeno religioso, está presente em todas as realizações do ser humano. O capitalismo não está apenas na fábrica ou supermercado, mas permeia todas as relações sociais e aspiração de futuro. Todos os dias são dias de culto do capitalismo e todos os lugares são lugares de culto do capitalismo. O tempo e espaço são condicionados pela exigência contínua de produção e consumo.

Esse culto capitalista, celebrado em todos os tempos e lugares, é diferente de qualquer outro culto, qualquer outra religião da história. Não há nele, segundo Benjamin, um caráter expiatório.

O capitalismo presumivelmente é o primeiro caso de culto não expiatório, mas culpabilizador. Nesse aspecto, tal sistema religioso é decorrente de um movimento monstruoso. Uma monstruosa consciência de culpa que não sabe como expiar lança mão do culto, não para expiar essa culpa, mas para torná-la universal, para martelá-la na consciência e, por fim e acima de tudo, envolver o próprio Deus nessa culpa, para que ele se interesse pela expiação. Esta, portanto, não deve ser esperada do culto em si, nem mesmo da reforma dessa religião, que deveria poder encontrar algum ponto de apoio firme dentro dela mesma; tampouco da recusa de aderir a ela. Faz parte da essência desse movimento religioso que é o capitalismo aguentar até o fim, até a culpabilização final e total de Deus, até que seja alcançado o estado de desespero universal, no qual ainda deposita alguma esperança (BENJAMIN, 2013, p. 22).

Dessa forma, o culto do capitalismo - não expiatório, mas culpabilizador - envolve a preocupação do ser humano até o final, até o último, sem nunca, contudo, oferecer qualquer realização última, sem nunca oferecer descanso, nunca oferecer satisfação, sentimento de "missão cumprida". O vazio existencial do ser humano, que este busca incansavelmente preencher, o vazio último, é envolvido num culto contínuo, interminável. Podemos dizer que esse culto escraviza toda busca por realizações do ser humano. É válida aqui a crítica que Alves faz à religião institucionalizada: para ele a institucionalização da experiência religiosa tende a matar a própria experiência ao prender o mistério da experiência em conceitos e dogmas (ALVES, 2007 , p. 39-40). Neste sentido, quando o sistema capitalista canaliza 
essa experiência religiosa, comum a cada pessoa, para seus próprios interesses, o efeito tende a ser muito semelhante.

Também não há graça no capitalismo. Aliás, a graça é um princípio teológico completamente ausente no capitalismo. É nesse ponto que Benjamin afirma que no capitalismo, "a religião não é mais reforma do ser, mas seu esfacelamento" (BENJAMIN, 2013, p. 22). Não há expiação, não há cura, não há restauração, não há salvação do ser, apenas o esfacelamento permanente, a condenação à produção e ao consumo e à produção para atender o consumo e consumo para dar vazão à produção, assim, interminavelmente.

$\mathrm{O}$ aspecto restante da religião capitalista consiste que o Deus do capitalismo "precisa ser ocultado e só pode ser invocado no zênite de sua culpabilização. O culto é celebrado diante de uma divindade imatura; toda representação dela e toda ideia sobre ela violam o mistério de sua madureza" (BENJAMIN, 2013, p. 22). Deus, enquanto símbolo do eterno, desaparece na lógica da religião capitalista. Resta o ser humano como suposto senhor do mundo - o Übermensch (o "superhomem", ou melhor, "além-humano" de Nietzsche). É analisando a sociedade industrial, isto é, capitalista, onde desaparece a transcendência que Tillich erige a seguinte crítica:

Achamos que somos mestres do mundo e de nós mesmos. Mas, na verdade, fazemos parte da realidade que criamos, objetos entre objetos, coisas entre coisas, parte da engrenagem da máquina universal, à qual devemos nos adaptar para que ela não nos esmague. Essa adaptação nos transforma em meios para fins que também, por sua vez, são meios, sem finalidade alguma. Resultam daí experiências de vazio e falta de sentido, de desumanização e alienação. Não mais achamos sentido na realidade que, em suas formas e estruturas, nada nos diz (TILLICH, 2009, p. 87).

Desaparece, no capitalismo, qualquer realidade final, qualquer ideia de destino. Também não há de fato um Übermensch que fizesse sua própria história. O ser humano é jogado para dentro da história como esteira de produção, num transcurso infindável e sem finalidade de produção e consumo. Para esse processo se dá o nome de coisificação. Nas palavras de Tillich: 
A forma técnica da produção monopolista não só de bens materiais como de bens espirituais, transformou o indivíduo, tanto na produção como no consumo em mera parte de uma máquina toda abrangedora, movida por forças anônimas. (...) Não só criou máquinas, todas iguais, mas também seres humanos "em série", condicionados pelo rádio, pelo cinema, pelos jornais e pelo ajustamento educacional, capaz de produzir o conformismo sub-humano em face desse imenso processo (TILLICH, 1992, p. 277).

Percebe-se, na crítica de Tillich, o processo alienante do capitalismo, não só como modo de produção, mas enquanto cultura que aliena o ser humano enquanto dessignificação e coisificação. O efeito existencial desse processo de alienação do ser humano se dá através da angústia (ou ansiedade).

Quando os seres humanos percebem que o destino humano lhes foi retirado das mãos, e que são jogados na rua por processos objetivos em que não participam, inseridos numa grande máquina como partes e instrumentos do amanhã, capaz de lhes conduzir à destruição, depois de amanhã, não se pode esperar outra coisa a não ser desespero (TILLICH, 1992, p. 277).

O ser humano, lançado para todos os lados pela força anônima do culto capitalista de Deus ausente, é como uma vítima sacrificial. A percepção do ser humano quanto a esse processo é de frustração, o que só aumenta seu vazio, cujo espaço o capitalismo pretende preencher com mais bens e símbolos descartáveis, sem aspecto de transcendência e eternidade. Apesar de sua desumanização, o ser humano é ainda humano o suficiente para sentir sua desumanização. Essa angústia é um recurso de sua superação.

Podemos perceber que Benjamin, ao definir o capitalismo como uma religião, aborda-o a partir de seus aspectos culturais e existenciais. Sua análise, portanto, atinge aspectos da profundidade da vida humana. O capitalismo, nesses termos, é mais que uma mediação de relações sociais e econômicas através de mercadorias, ele é uma mediação de sentidos através de mercadorias. A compreensão do capitalismo como religião permite aproximações de críticas teológicas como as de Rubem Alves e Paul Tillich. A seguir desdobramos a dinâmica religiosa do capitalismo do ponto de vista dos excluídos. 


\section{O consumismo como elemento religioso}

O ser humano é mais que um ser biológico, é também simbólico e, por isso, busca não só a satisfação de suas necessidades biológicas, mas busca razões e sentido para viver. $\mathrm{Na}$ atualidade, a grande maioria das pessoas compartilha os sonhos e esperanças que são oferecidos pelos setores dominantes da sociedade. Jung Mo Sung nos lembra que, historicamente, isso foi assim. A população massificada sempre foi, em certa medida ,influenciada pela classe dominante, isto é, seus sonhos e aspirações são condicionados mediante a influência econômica, social e cultural das classes dominantes. No entanto, atualmente tal fenômeno alcançou um nível nunca antes registrado (SUNG, 2002, p. 09). Segundo Sung:

Os especialistas em marketing e propaganda perceberam que, na nossa cultura de consumo, o mais importante no ato de consumir não são as características do produto ou a sua capacidade de satisfazer as necessidades ou desejos do consumidor, mas sim o significado pessoal, interpessoal e social do ato de consumir determinadas marcas e mercadorias. Isto é, a função primaria de mercadoria deixou de ser a de satisfazer os desejos dos consumidores e passou a ser a de comunicar sentidos. Sonhos e esperanças de uma grande parte da população mundial hoje têm a ver com o consumo de determinados símbolos-mercadorias. Os sentidos e anseios mais profundos da existência humana são expressos através de marcas e mercadorias (SUNG, 2002, p. 09).

O principal produto do capitalismo para consumo não são as mercadorias, as "coisas", mas os símbolos, os sentidos, os significados que essas mercadorias representam. O consumo não atende preocupações pontuais, como alimento e vestiário, mas "estilo de vida", "modo de vida" representados pelo produto $a$ ou $b$. De modo semelhante, Guy Debord aborda a espetacularização que o capitalismo conduziu a sociedade, espetáculo não como "um conjunto de imagens, mas uma relação social entre pessoas, mediada por imagens" (DEBORD, 1997, p. 14).

Essa constatação parece explicar a aceitação do sistema capitalista por parte da grande maioria da população mundial, inclusive dos pobres, estes que sustentam os privilégios da classe dominante. O capitalismo não é só um sistema de produção e consumo de mercadorias, mas de 
significados que mediam relações com o outro e consigo mesmo. $\mathrm{O}$ capitalismo, com todos seus mecanismos e facetas, consegue dialogar com o caos humano, de forma a obter lucro. A miséria existencial humana move a sociedade do consumo. O "suspiro dos oprimidos" é direcionado para dentro dos shoppings centers, os templos do capitalismo moderno. O fetiche das mercadorias representa para os indivíduos urbanos a possiblidade de salvação aqui e agora. Representa para os pobres a possibilidade mentirosa de existirem, de acessarem a vida plena. Na sociedade capitalista "ter" significa "ser", logo não ter significa não ser, isto é, não existir, o que representa o maior medo humano, o caos total, pois os inexistentes no mundo capitalista são invisibilizados, anulados e excluídos. São jogados "lá onde há choro e ranger de dentes" (Mateus 24.51). Nessa direção, vai a constatação de Zygmunt Bauman:

Pobres daqueles que [...] permanecem presos a um único bem em vez de flanar entre um sortimento amplo e aparentemente inesgotável. Tais pessoas são os excluídos na sociedade de consumo, os consumidores falhos, os inadequados e os incompetentes, os fracassados - famintos definhando em meio à opulência do banquete consumista (BAUMAN, 2004, p. 50).

Tal lógica é propagada com seu domínio hegemônico sobre as mídias, as quais são responsáveis por criar no consumidor os desejos, os sonhos, os horizontes utópicos, que são utilizados pelo próprio sistema. O capitalismo moderno não só se utiliza da experiência e preocupação religiosa, como definida por Alves ou Tillich, mas consegue manipulá1a. O sistema cria os desejos direcionados aos objetos que oferece para o consumo. Uma das formas que utiliza para promover isso é a propagação do desejo mimético. Conforme esclarece Nestor Míguez, "[...] é desnecessário dizer que a indústria da propaganda baseia-se em promover esse tipo de desejo: queremos não apenas os objetos que nos comerciais as pessoas felizes têm, mas queremos também aquilo que as faz tão felizes" (MÍGUEZ, 2012, p. 67).

Nesse horizonte forjado e fundado sobre o consumo, não resta lugar para aqueles que não conseguem se adaptar às exigências do sistema. Não há lugar para os pobres, para os socialmente excluídos 
(SUNG, 2002, p. 10). O fracasso do sistema é encoberto e suas vantagens e utopias são exaltadas, uma promessa que não se alcança. $\mathrm{Na}$ sociedade do consumo, quem não tem, simplesmente, não existe. Como consequência, centenas de milhares de pessoas tornam-se vítimas desse sistema que prioriza o lucro e o consumo, elas são as vítimas sacrificais que precisam morrer para a implantação do mercado (SUNG, 1992, p. 96-97). O único caminho que o sistema oferece para os socialmente excluídos é a ideia, geralmente falsa, da ascensão econômica e social pelo trabalho e consumo, ou seja, a ideologia da meritocracia. Para ser é preciso ter, e para ter é preciso trabalhar arduamente para seu patrão (SUNG, 2002, p. 09). Não existe teologia da graça no sistema. A meritocracia é o caminho que o capitalismo oferece para a salvação. E tal ideologia é decorada pelos funcionários e assumida nos discursos dos patrões. A salvação para o pobre é "ser alguém na vida", frase que muitos professores das escolas públicas têm como imperativo ao aconselhar seus alunos. O Reino de Deus é visto pelos capitalistas como o lugar onde os indivíduos podem consumir tudo o que eles oferecem. Os valores do Reino, que Jesus anuncia, como a solidariedade, a partilha, a justiça, são substituídos pela poder mágico do egoísmo e da acumulação (SUNG, 1992, p. 93-94).

Tal constatação explica a presença do hábito de consumo desenfreado também entre os pobres, onde podemos facilmente observar casos de trabalhadores e trabalhadoras que ao ganhar uma quantidade razoável de dinheiro imediatamente gastam em coisas aparentemente supérfluas. Quem observa esse fenômeno pode ficar indignado e se utilizar dessa realidade para justificar posições de indiferença com os "pobres consumistas". O que escapa nessa observação é o fato de que consumir, não as mercadorias, mas os símbolos, os sentidos que a sociedade de consumo oferece, significa a chance de se tornarem um pouco mais gente. Esse fenômeno se constitui em uma verdadeira mística do consumo. Sabe-se da natureza paliativa de tal mística e os efeitos perversos e desumanos que ela tem na vida das pessoas, fadadas a trabalharem a vida toda sem perspectiva de emancipação. Torna-se evidente que a salvação oferecida pelo sistema é para poucos. Todos são chamados, mas poucos são escolhidos, bem poucos (Mateus 22.14). 
O "inferno" dos condenados sustenta o banquete servido no "céu" aos convidados de honra do sistema.

De forma resumida pode-se afirmar que a busca humana pelo transcendente é manipulada pelo sistema capitalista através do consumismo, seu aspecto medular na atualidade. A necessidade da busca humana por "ares saudáveis" é contaminada pela "fumaça tóxica" da "fábrica capitalista" que mata o ser humano justamente na sua essência mais revolucionária, isto é, sua desacomodação com a realidade opressora da vida. É possível postular a metáfora de um mergulhador que respira através de um caniço que tem sua extremidade fora da água. Ele tem, dessa forma, um mundo de ar a sua disposição. Essa respiração, para os respectivos autores trabalhados, é o que podemos chamar de experiência religiosa. No entanto, o sistema capitalista coloca um balão na ponta do caniço, de modo que o mergulhador só pode respirar o que está dentro do balão. O balão dispõe de uma experiência fechada e limitada de respiração e, com o tempo, sufocante. O balão é/está preenchido com as promessas de sentido oferecidos pelo capitalismo através de mercadorias e o mergulhador é induzido a pensar que, se o sistema tirar o balão da ponta do caniço, ele morrerá afogado, uma vez que se foi induzido a respirar as mercadorias e o conjunto de sentidos provenientes do consumismo. Nessa direção podese compreender a observação de Bauman sobre a sociedade consumista:

Pode-se dizer que, numa sociedade consumista, todo comércio e produtos e serviços, constitui, antes de mais nada, farmácias [...]. Presume-se e espera-se que a aquisição e o consumo dessas mercadorias consigam aplacar desconfortos ou dores que de outra forma continuariam a inflamar e a infeccionar; melhor ainda, espera-se que esses atos evitem reações desagradáveis que sem dúvida se abaterão sobre o comprador preguiçoso e indolente (BAUMAN, 2011, p. 85).

O capitalismo, portanto, trata-se de uma religião onde as mercadorias constituem-se símbolos que prometem sentidos e modos de vida. No consumo, não se adquire meras coisas, mas significados para a vida e essas coisas são os símbolos que colocam ordem no caos, fazem a vida ser ou parecer significativa: cheia de significados. Por essa razão, trata-se de uma religião do ter e não do ser, pois uma vez o crente não possuindo os objetos de significado para a vida (as 
mercadorias) não possui mais significado nessa religião. A salvação da religião capitalista se resume na posse desses objetos que, com um prazo muito curto, tornaram-se obsoletos, lançando a pessoa a uma nova busca por outros objetos, sem nunca satisfazer a procura por salvação. Não há qualquer graça nessa religião. E a maior parte das pessoas, isto é, as pobres, está condenada a nunca satisfazer sua procura por esses objetos de sentido para a vida. A religião do consumo se resume à culpabilização e à condenação. Nesse cenário, qualquer espiritualidade que anseie por ser libertadora deve assumir uma perspectiva contrária à lógica consumista do sistema capitalista.

\section{Considerações Finais}

Por fim, podemos afirmar que o sistema capitalista consegue direcionar o caos dos indivíduos contemporâneos para o consumo. A partir do domínio sobre as mídias, não só direciona o que Alves chama de experiência religiosa primordial e Tillich chama de preocupação última, mas as manipula desde a raiz. O capitalismo pode ser considerado uma religião, conforme já afirmava Benjamin, porque dialoga com a profundidade religiosa e, a partir disso, oferece a salvação através do consumo, assumindo a meritocracia como caminho da salvação e o "trabalho-consumo-existo" como mística do cotidiano. Os pobres estão condenados ao inferno, mas acreditam que a partir da meritocracia podem acessar o "Reino dos céus", onde poderão saciar seus desejos criados pela própria lógica capitalista. No entanto, o capitalismo enquanto religião carrega uma séria deficiência. Por direcionar todo caos humano - este que é a origem de toda forma de religião, segundo a abordagem de Alves e Tillich - para o consumo, os seres humanos são transformados em consumidores compulsivos que não conseguem preencher seus dramas internos, a não ser de forma paliativa. Seu resultado, não expiatório, mas culpabilizador, é de frustração existencial, perca da identidade por parte do indivíduo e a desintegração da coletividade.

Neste cenário, a Igreja, provocada pela mensagem do Reino de Deus, é convidada a assumir uma espiritualidade libertadora, que ouse sonhar e vivenciar os sonhos que o sistema não vende. 
Uma espiritualidade profética, que, ao lado das pessoas excluídas e marginalizadas pela lógica capitalista, assuma a direção contrária do sistema, deixando-se guiar pelos valores do Reino como a solidariedade, o amor, a justiça, e a profecia diante das injustiças estruturais.

\section{Referências}

ALVES, Rubem. O enigma da religião. 6. ed. Campinas: Papirus, 2007.

O que é religião?. 14. ed. São Paulo: Loyola, 2013.

BAUMAN, Zygmunt. Amor líquido: sobre a fragilidade dos laços humanos. Rio de Janeiro: Jorge Zahar, 2004.

Zahar, 2011.

44 cartas do mundo líquido moderno. Rio de Janeiro:

BENJAMIN, Walter; LÖWY, Michael (ORG.). O capitalismo como religião. Trad.: Nélio Schneider e Renato Ribeiro Pompeu. São Paulo: Boitempo, 2013.

DEBORD, Guy. A sociedade do espetáculo. Trad.: Estela dos Santos Abreu. Rio de Janeiro: Contraponto, 1997.

MÍGUEZ, Néstor Oscar; RIEGER, Joerg; SUNG, Jung Mo. Para além do espírito do império: novas perspectivas em política e religião. São Paulo: Paulinas, 2012.

SUNG, Jung Mo. Deus numa economia sem coração: pobreza e neoliberalismo. São Paulo: Paulinas, 1992.

Sujeito e sociedades complexas: para repensar os horizontes utópicos. Petrópolis: Vozes, 2002.

TILLICH, Paul. A Era Protestante. Com um ensaio final de James Luther Adams. Trad.: Jaci Maraschin. São Paulo: Instituto Ecumênico de PósGraduação em Ciências da Religião, 1992.

Sinodal, 2002.

Dinâmica da Fé. 7. ed. Trad.: Walter O. Schlupp. São Leopoldo:

Teologia da Cultura. Com apresentação do Dr. Jorge Pinheiro. Trad.: Jaci Maraschin. São Paulo: Fonte Editorial, 2009.

Teologia Sistemática. 6 ed. rev. Trad.: Getúlio Bertelli e Geraldo Korndörfer. São Leopoldo: Sinodal/EST, 2011. 


\section{Meios eletrônicos}

AFP. Desigualdades crescem no mundo, especialmente nos Estados Unidos. UOL Economia. 2017. Disponível em: <https:/economia.uol.com.br/noticias/ afp/2017/12/14/desigualdades-crescem-no-mundo-especialmente-nos-estadosunidos.htm>. Acesso em 14 de Jun 2018.

CUNHA, Joana. 22\% dos brasileiros vivem abaixo da linha da pobreza, diz estudo. Folha de São Paulo. 2017. Disponível em: < https://www1.folha.uol. com.br/mercado/2017/10/1931680-22-dos-brasileiros-vivem-abaixo-da-linhada-pobreza-diz-estudo.shtml> Acesso em 06 de Ago 2018.

GOMES, Helton Simões. Super-ricos ficam com $82 \%$ da riqueza gerada no mundo em 2017, diz estudo. G1. 2018. Disponível em: < https://g1.globo. com/economia/noticia/super-ricos-ficam-com-82-da-riqueza-gerada-no-mundoem-2017-diz-estudo.ghtml>. Acesso em: 14 de Jun 2018.

REDE VIDA. A vida que vale a pena ser vivida. Disponível em: $<$ https:// www.youtube.com/watch?v=WZIRqNsgC6c>. Acesso em: 14 de Jun de 2018. ORGANIZAÇÃO DAS NAÇÕES UNIDAS. ONU pede ação internacional para enfrentar as causas da pobreza. ONUBR. Disponível em: https:// nacoesunidas.org/onu-pede-acao-internacional-para-enfrentar-as-causasda-pobreza/ Acesso em: 06 de Ago de 2018. 